\title{
ACESSIBILIDADE NA ARBORIZAÇÃO URBANA: PERCEPÇÃO DE DEFICIENTES VISUAIS SOBRE A MOBILIDADE EM ESPAÇOS PÚBLICOS ARBORIZADOS
}

\author{
ACCESSIBILITY IN URBAN AFFORESTATION: PERCEPTION OF VISUAL \\ IMPAIRMENT ON MOBILITY IN ARBORIZED PUBLIC SPACES
}

Ana Maria Jerônimo Soares ${ }^{1}$, Rodrigo Leone Alves², Elma Núbia de Medeiros Araújo Targino³

\section{RESUMO}

A presença de árvores é fator importante para a qualidade de vida da população nos grandes centros urbanos. Apesar dos benefícios da arborização na função socioambiental, tal processo, quando implantado de forma inadequada, não está isento de diversos tipos de danos que comprometem a mobilidade, especialmente dos indivíduos com deficiências físicas e sensoriais. Este artigo objetiva avaliar a percepção de deficientes visuais sobre as principais dificuldades e limitações encontradas nos seus trajetos em áreas arborizadas. Os participantes da pesquisa eram residentes da cidade de Natal RN. Para a coleta de dados realizou-se entrevistas, baseadas em um questionário semiestruturado, com 15 munícipes cegos. Realizou-se a análise dos conteúdos dos relatos, e os resultados apontam que os deficientes visuais reconhecem a importância da arborização para a qualidade de vida nos centros urbanos. Porém, já vivenciaram situações conflituosas que a bengala, principal instrumento de suporte à locomoção, não consegue identificar. Tais como, árvores em locais inadequados obstruindo a passagem, podas mal posicionadas, galhos baixos e com espinhos, raízes altas que podem provocar a queda, entre outros obstáculos, que interferem na orientação e locomoção dessas pessoas, prejudicando sua independência, fato que reflete a necessidade de planejamento e acompanhamento por parte dos órgãos responsáveis.

Palavras-chave: Percepção ambiental; Mobilidade de Cegos; Planejamento Urbano; Políticas Públicas.

\begin{abstract}
The presence of trees is an important factor for the quality of life of the population in large urban centers. Despite the benefits of afforestation in the socio-environmental function, this process, when improperly deployed, is not exempt from several types of damages that compromise mobility, especially of those with physical and sensory impairments. This study aims to evaluate the perception of visually impaired people about the main difficulties and limitations found in their paths in forested areas. The participants of the survey were residents of Natal - RN city. To data collection, interviews were conducted through a semistructured questionnaire applied to 15 blind residents. The content of the reports was analyzed, and the results show that the visually impaired recognize the importance of afforestation for the quality of life in urban centers. However, they have experienced conflicting situations that the white cane, the main instrument to support locomotion, cannot identify. Such as trees in inappropriate places obstructing the passage, pruning poorly positioned, low branches and with thorns, high roots that can cause the fall, among other obstacles, that interfere in orientation and locomotion of these people, hampering their independence, fact that reflects the need for planning and monitoring by the responsible bodies.
\end{abstract}

Keywords: Environmental perception; Mobility of Blind; Urban planning; Public policy.

\footnotetext{
Recebido em 26.07.2017 e aceito em 02.10.2017

1 Graduanda em Administração pela Universidade Potiguar. Natal/RN. Email: amaria.soa@gmail.com

2 Engenheiro Eletricista. Dr., Professor efetivo do Instituto Federal do Rio Grande do Norte. Nova Cruz/RN. Email: rodrigo.leone@ifrn.edu.br

3 Graduanda em Administração pela Universidade Potiguar. Natal/RN. Email: elmaanubiaa@gmail.com
} 


\section{INTRODUÇÃO}

A prática de arborização urbana, definida como a vegetação de porte arbóreo existente nas cidades (OLIVEIRA et al., 2016a; OLIVEIRA et al., 2016b; SOARES; ALVES, 2016), além de exercer significativa função socioambiental, desempenha inúmeros papéis na moderação climática e na sustentabilidade própria das cidades (ARMSON; STRINGER; ENNOS, 2013), proporcionando ao cidadão uma vivência harmoniosa em ambientes construídos (SILVA; FIDELIS; CASTRO, 2011; GODECKE; MAURíCIO, 2015).

Não obstante aos benefícios do plantio de árvores nos espaços públicos, apontados como pré-requisitos para um melhor padrão de vida nas cidades, destaca-se que a relação da referida técnica não está imune à incidência de transtornos para a locomoção de pedestres, sobretudo, para as pessoas com deficiência e mobilidade reduzida. Em outras palavras podese dizer que quando não há prévio estudo e planejamento, o ato de arborizar acarreta mais conflitos do que benefícios (OLIVEIRA et al., 2017), e consequentemente, seus efeitos adversos impactam sobre a mobilidade e acessibilidade.

Arborizar não significa plantar árvores aleatoriamente em qualquer lugar, isto é, existe a árvore certa para o local certo e para isso existem diversas normas, bem como diretrizes legais a serem seguidas (RIBEIRO, 2009; SANTOS et al., 2015). Assim, um projeto de arborização previamente planejado que possibilita, de forma simultânea, o adequado uso do solo sem interferir na locomoção de pedestres, condiciona a acessibilidade urbana. Desta forma, quando há problemas e limitações para a mobilidade e o livre acesso de pessoas a determinados ambientes, o impedimento está no espaço, que não é capaz de prover acesso à todos as pessoas, desrespeitando assim, suas necessidades (RUOSO, 2012; HAUBRICHT; FIORINI, 2014; SOARES; ALVES, 2016).

De acordo com Soares e Alves (2016), consta na Constituição Federal (art. 30 e art. 182) diretrizes que apontam o dever do município de arborizar e preservar tal sistema. Em contrapartida, no que tange à natureza jurídica, destaca-se que o Decreto Federal número $5.296 / 2004$ estabelece que a acessibilidade para os deficientes deve ser garantida em todas as intervenções urbanas (RIBEIRO; VARELA, 2015). De forma análoga, a Lei 10.098/2000 apresenta aspectos normativos que asseguram a redução de barreiras físicas em vias e espaços públicos, de transporte, comunicação e mobiliário. Assim, ambos os paradigmas, arborização e acessibilidade, devem ser atendidos de forma sinérgica.

Segundo as formulações de Ribeiro e Varela (2015), a circulação livre e segura de pessoas com deficiência, bem como qualquer pedestre, não se trata de uma mera questão de sensibilização, pelo contrário, é um direito reconhecido legalmente. Ademais, conforme esmiúça Licht (2015), a acessibilidade urbana e a mobilidade, se configuram como importantes 
indicadores para mensurar a exclusão social, aspecto que evidencia que tais componentes são indispensáveis à dinâmica das cidades, bem como à maximização da qualidade de vida da população urbana.

Alguns eventuais aspectos que podem impor limitações aos deficientes visuais em seus trajetos são: tocos residuais e cortes em ramos (podas) mal feitos e a certa altura do alcance da face dos pedestres, árvores de grande porte em calçadas estreitas que dificultam a passagem, raízes altas, galhos baixos, rachaduras nas calçadas em virtude das características da espécie arbórea e sua raiz (SOARES; ALVES, 2016), entre outros fatores que não podem ser facilmente identificados pela bengala, que geralmente é a ferramenta de auxílio para a locomoção do referido grupo.

Segundo esta perspectiva, com base na relevância do tema e à escassez de informações em pesquisas nacionais e internacionais, este trabalho discorre sobre o viés social do conceito de acessibilidade e mobilidade, tratando tais termos como parte essencial do processo de implementação da arborização no espaço urbano. Assim, objetiva-se analisar a percepção de indivíduos cegos com relação ás potencialidades, dificuldades e limitações enfrentadas no passeio público em áreas arborizadas, verificando se a arborização afeta na mobilidade desses indivíduos. Desta forma, o presente trabalho corrobora para respaldar, por meio de estudos acadêmicos, a importância da acessibilidade/mobilidade como fator essencial a ser considerado na formalização dos planos e projetos de arborização, implicando em inclusão social e equidade na apropriação das cidades e dos serviços urbanos.

\section{MATERIAL E MÉTODOS}

Quanto aos procedimentos metodológicos, o presente estudo adota perspectivas qualitativa e quantitativa, sendo uma pesquisa de cunho descritivo, uma vez que busca interpretar e conhecer determinada realidade, expondo assim, as características de um fenômeno ou população, servindo de base para explicar tais fenômenos, sem o compromisso de modifica-lo (GIL, 2002).

Este estudo pode ser caracterizado como estudo de caso, tendo em vista que busca analisar o como e o porquê de uma situação, destacando suas características prioritárias e essenciais para a melhor compreensão do fenômeno investigado (YIN, 2010).

A pesquisa realizou-se com um número restrito de cegos, residentes na cidade de Natal, no estado do Rio Grande do Norte. Julga-se importante destacar a dificuldade inicial de se encontrar números oficiais inseridos no Censo Demográfico, especificamente com relação aos cegos residentes em Natal, por este motivo, não se obteve dados da população total de 
deficientes visuais no município. A investigação contou com a participação de 15 sujeitos de ambos os gêneros, bem como, com faixas etárias variadas. A coleta de dados ocorreu no mês de abril de 2017. Como critério de seleção pode-se destacar a disponibilidade e interesse, quando o convite para participar da entrevista foi feito pelos pesquisadores, quando já se tinha alguma experiência com passeios nas vias públicas da cidade.

Os dados foram coletados por meio de entrevista, baseada em um questionário semiestruturado composto por 10 perguntas, conforme apresentado na Figura 1, relacionadas à caracterização do perfil da pessoa com deficiência, tendo algumas questões abertas, para que os indivíduos comentassem suas percepções e experiências diante da situação da arborização nas vias públicas da cidade, seus julgamentos sobre as possíveis potencialidades, dificuldades e limitações vivenciadas ao caminhar em locais com árvores e eventuais conflitos entre as árvores e a locomoção dos deficientes.

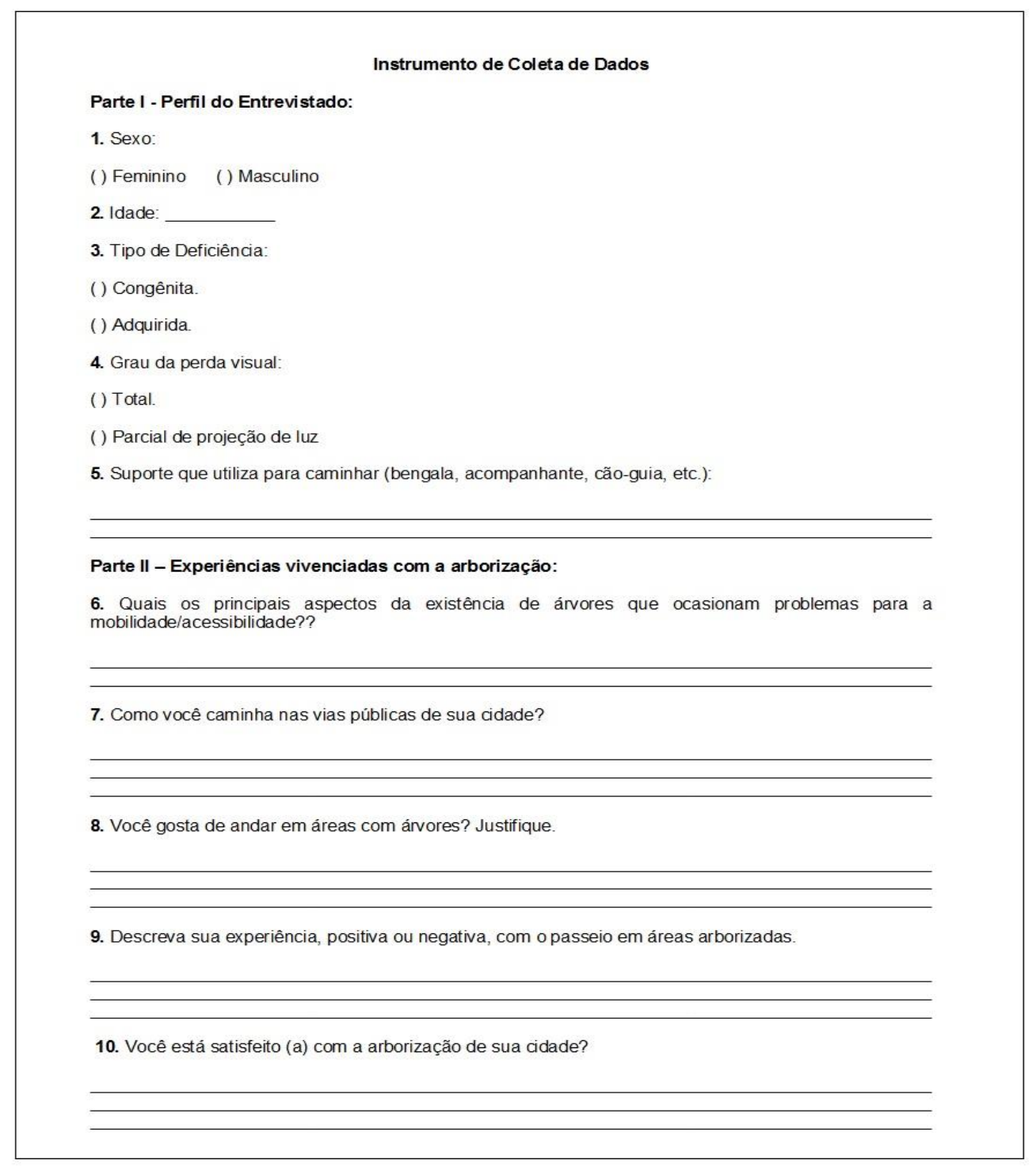

Figura 1. Questionário utilizado na entrevista

Figure 1. Questionnaire used in the interview 
Nesse contexto da coleta de dados, a entrevista face a face, forneceu muito mais dados do que as informações escritas e analisadas, tratando-se de um processo de relação interpessoal direto, quando o pesquisador tinha acesso aos sentimentos dos entrevistados, suas angústias, suas vivências no processo de convívio com a arborização urbana, e outras vivências que não estão expostas na pesquisa, que produziram reflexões e discussões.

Para descrição e compreensão dos resultados, na etapa de organização e avaliação dos dados utilizou-se a estatística descritiva e a técnica de análise de conteúdo, seguindo as três etapas propostas por Bardin (2002): pré-análise, que diz respeito à organização do trabalho e definição dos procedimentos; exploração do material (codificação e categorização), que consiste no processo de apresentação dos resultados da pesquisa, isto é, no recorte dos registros e reunião dos elementos fundamentais, e tratamento dos resultados, que trata-se da interpretação dos resultados brutos. Assim, realizou-se interpretações e inferências entre os resultados e as informações explanadas na literatura.

\section{RESULTADOS E DISCUSSÃO}

\section{Perfil dos Entrevistados}

Destaca-se que a diferenciação de gênero, bem como faixa etária, não é de um fator que exerce eventual influência no resultado da pesquisa, todavia julga-se relevante realizar uma breve caracterização dos indivíduos participantes da pesquisa. Assim, dos sujeitos envolvidos, 8 eram do sexo masculino e 7 do sexo feminino. Com relação à faixa etária, destaca-se que estes indivíduos apresentaram idades entre 17 e 51 anos.

No que tange o tipo da deficiência, identificou-se que 9 são pessoas com deficiência visual congênita (cegos desde o nascimento) e 6 possuem cegueira adquirida. Cabe destacar ainda que com relação ao grau da perda, 12 possuíam perda total da visão, enquanto que 3 apresentam perda parcial de projeção de luz.

Ademais, quando questionados sobre como caminhavam pelas vias públicas, os 15 sujeitos destacaram a bengala como ferramenta de suporte, e destes, 5 mencionaram que além de utilizar a bengala precisam do auxílio de acompanhantes para se locomoverem pelas ruas. 


\section{Percepção das Pessoas com Deficiência Acerca das Experiências Vivenciadas com a Arborização}

A análise da percepção das pessoas com deficiência envolveu as constatações mais frequentes nas falas dos indivíduos, de modo que os resultados foram agrupados em temas/categorias. O quantitativo de respostas brutas e o percentual de respondentes para o questionamento acerca dos principais aspectos que causam transtornos para a locomoção em locais com espécies arbóreas está representado na Tabela 1.

Tabela 1. Aspectos que ocasionam problemas para a mobilidade/acessibilidade

Table 1. Aspects that cause problems for mobility/accessibility

\begin{tabular}{lcc}
\hline Conflitos entre árvores e a mobilidade/acessibilidade & $\begin{array}{c}\text { No de } \\
\text { Respostas }\end{array}$ & $\begin{array}{c}\text { Percentual de } \\
\text { Respondentes }\end{array}$ \\
\hline $\begin{array}{l}\text { Árvores de grande porte plantadas em calçadas estreitas } \\
\text { que interferem a passagem }\end{array}$ & 15 & $100 \%$ \\
$\begin{array}{l}\text { Galhos baixos que alcançam a altura do rosto de um } \\
\text { pedestre }\end{array}$ & 15 & $100 \%$ \\
$\begin{array}{l}\text { Tocos residuais resultantes de cortes ou podas de } \\
\text { árvores }\end{array}$ & 12 & $80 \%$ \\
Raízes altas & 15 & $100 \%$ \\
Calçadas rachadas e esburacadas pelas raízes & 14 & $93,33 \%$ \\
Árvores com frutos grandes que se espalham pelo chão, & 13 & $86,67 \%$ \\
em área de passeio público & 15 & $100 \%$ \\
Galhos com espinhos & 11 & $73,33 \%$ \\
\hline Plantas rasteiras com espinhos
\end{tabular}

Os principais conflitos, da arborização com a mobilidade/acessibilidade das pessoas com deficiência visual, apontados são: a existência de árvores de grande porte em calçadas estreitas, galhos baixos, raízes altas, galhos espinhosos (100\% das respostas), calçadas danificadas pelas raízes (93,33\% das respostas), árvores que possuem frutos que se espalham pelo chão (86,67\%), podas malfeitas que resultam em tocos residuais ( $80 \%$ das respostas), plantas rasteiras com espinhos (73,33\%). Tal como Soares e Alves (2016) afirmam, esses fatores acarretam vulnerabilidades na locomoção dos indivíduos.

Por mais simples que estes aspectos parecem, os órgãos responsáveis pela arborização precisam atentar para estes fatores, pois um indivíduo sem deficiência poderá superar/desviar estes obstáculos facilmente, mas uma pessoa com deficiência visual terá significativa dificuldade. A ineficiência na execução dos serviços acarreta sérias dificuldades na acessibilidade e mobilidade urbana, gerando movimentos que ilustram a falta de inclusão social, evidenciando as carências urbanas. 
Inegavelmente, a ação de arborizar não significa apenas atender a demanda crescente por áreas verdes no espaço urbano, mas sim alinhar tal procura às necessidades de todos os cidadãos, deficientes ou não, e requer corresponsabilidade e comprometimento de todos os agentes envolvidos em sua produção. (SOARES; ALVES, 2016; OLIVEIRA et al., 2017).

No que diz respeito aos relatos dos deficientes sobre as experiências vivenciadas com a arborização local, o Quadro 1 apresenta os comentários para determinadas categorias. Tendo em vista que a pesquisa contou com oito homens e 7 mulheres, estes indivíduos foram identificados no quadro com $\mathrm{H}$ (Homem), de 1 a 8 , e $\mathrm{M}$ (Mulher), de 1 a 7.

\begin{tabular}{|c|c|c|}
\hline $\begin{array}{l}\text { Categoria } \\
\text { Analisada }\end{array}$ & Homens (H) & Mulheres (M) \\
\hline $\begin{array}{c}\text { Como } \\
\text { caminha }\end{array}$ & $\begin{array}{l}\text { - "Busco independência e caminho sem } \\
\text { acompanhante, apesar de enfrentar transtornos, } \\
\text { tanto da interferência de árvores quanto de outras } \\
\text { estruturas urbanas" (H1); } \\
\text { - "Caminho sempre acompanhado" (H2); } \\
\text { - "É perigoso, mas tento sair sozinho para ter um } \\
\text { pouco de independência" (H3); } \\
\text { - "Saio pouco de casa, mas consigo sair sozinho..." } \\
\text { (H4); } \\
\text { - "Caminho sozinho, temos que enfrentar as } \\
\text { barreiras..." (H5); } \\
\text { - “... Já passei muitas dificuldades tentando andar } \\
\text { sozinho, prefiro sair acompanhado." (H6); } \\
\text { - "Caminho sozinho, mas saio pouco, apenas para } \\
\text { locais próximos, quando preciso" (H7); } \\
\text { - "Caminho sozinho com a bengala, as vezes } \\
\text { acompanhado, depende do local que vou, mas } \\
\text { geralmente saio só." (H8). }\end{array}$ & $\begin{array}{l}\text { - "Mesmo com a bengala eu não saio } \\
\text { de casa sozinha." (M1); } \\
\text { - "Consigo caminhar sozinha com a } \\
\text { bengala" (M2); } \\
\text { - "Saio sozinha quando preciso" } \\
\text { (M3); } \\
\text { - “... Tenho medo de cair, sofrer } \\
\text { algum acidente e me machucar.... } \\
\text { Saio acompanhada” (M4); } \\
\text { - "Dificuldades eu sinto, mas saio } \\
\text { sozinha com frequência" (M5); } \\
\text { - "Caminho sozinha, mas as vezes } \\
\text { preciso que alguém me acompanhe” } \\
\text { (M6); } \\
\text { - "Caminho acompanhada, é difícil } \\
\text { caminhar sozinha" (M7). }\end{array}$ \\
\hline
\end{tabular}

Quadro 1. Caminhada em locais com árvores

Chart 1. Walk in places with trees

Percebe-se, que alguns indivíduos que já passaram por situações conflituosas como tropeços em raízes, impossibilidade de caminhar com árvores obstruindo a passagem, quedas e outros obstáculos, sofreram certo impacto psicológico, uma vez que estes afirmam que "é perigoso", demonstrando que sentem medo de caminhar em locais arborizados, pois temem cair e se machucar.

Cabe destacar que o fato de os indivíduos com deficiência visual apresentarem, muitas vezes, eventual receio de se locomoverem em locais com árvores, não significa dizer que tais indivíduos não gostem da existência de espécies arbóreas, tampouco que não reconheçam sua importância para a manutenção socioambiental dos centros urbanos. 
A questão é que muitas vezes árvores plantadas em locais inadequados, sobretudo nas calçadas, interferem a independência na locomoção de tais sujeitos. Cabe salientar que uma parte dos prejuízos poderia ser eliminada mediante legislação e controle das atividades urbanas, bem como pelo seu planejamento, de modo a ampliar a arborização de ruas de forma qualitativa e quantitativa, sem limitar a circulação e qualidade de vida da população. O Quadro 2 apresenta a análise dos comentários acerca do gosto das pessoas com deficiência por áreas arborizadas.

\begin{tabular}{|c|c|c|}
\hline $\begin{array}{l}\text { Categoria } \\
\text { Analisada }\end{array}$ & Homens (H) & Mulheres (M) \\
\hline $\begin{array}{l}\text { Gosto por } \\
\text { áreas com } \\
\text { árvores }\end{array}$ & $\begin{array}{l}\text { - "Gosto. Faz sombra, o ar é bom, mas sinto } \\
\text { dificuldades para caminhar, dependendo do } \\
\text { local e da árvore." (H1); } \\
\text { - "Não gosto muito porque é ruim de passar } \\
\text { nas calçadas com árvores." (H2); } \\
\text { - "Não gosto, tenho dificuldades para desviar } \\
\text { delas, até já cai..." (H3); } \\
\text { - "Gosto bastante, árvore sempre é bom, faz } \\
\text { sombra." (H4); } \\
\text { - "Até gosto, mas é complicado para quem é } \\
\text { cego. A gente não vê os buracos perto das } \\
\text { árvores, os ramos baixos..." (H5); } \\
\text { - "Gosto, reduz o calor." (H6); } \\
\text { - "Gosto, mas prefiro quando as árvores não } \\
\text { são muito grandes para ter mais espaço para } \\
\text { a gente passar." (H7); } \\
\text { - "Mais ou menos, é bom para a cidade, para o } \\
\text { clima, mas para caminhada de quem não } \\
\text { enxerga dificulta..." (H8). }\end{array}$ & $\begin{array}{l}\text { - "É agradável, mas tem árvores que a } \\
\text { gente não consegue identificar e nos } \\
\text { atrapalhamos, dificulta muito." (M1); } \\
\text { - "Sim, gosto." (M2); } \\
\text { - "Gosto. Mas sei que elas precisam ser } \\
\text { adequadas." (M3); } \\
\text { - "Não, sempre ando acompanhada e me } \\
\text { dizem que as árvores foram plantadas } \\
\text { erradas, e que ocupam toda a área } \\
\text { destinada aos pedestres, dificultando a } \\
\text { locomoção" (M4); } \\
\text { - "Em partes. Eu gosto se não dificultarem } \\
\text { a minha caminhada." (M5); } \\
\text { - "Gosto, mas já tive dificuldades de } \\
\text { caminhar com árvores..." (M6); } \\
\text { - "Gosto de árvores, mas não gosto de } \\
\text { caminhar onde tem muitas, porque sinto } \\
\text { dificuldade em passar pelas raízes longas } \\
\text { e altas, os galhos e buracos." (M7). }\end{array}$ \\
\hline
\end{tabular}

Quadro 2. Gosta de áreas com árvores?

Chart 2. Do you like areas with trees?

A opinião que se constrói acerca da problemática em questão é que no geral, tanto os indivíduos que caminham autonomamente quanto os que caminham com o auxílio de acompanhantes, gostam da arborização e de seus potenciais benefícios, tais como sombra, amenização do calor entre outros, porém sentem dificuldades em circularem em locais com árvores.

Nesta perspectiva, depreende-se que o problema não é a presença de árvores, mas a forma e o local onde estas foram implementadas (KRAMER; KRUPEK, 2012; FARIA et al., 2013; SOARES; ALVES, 2016), fato que reflete eventual falha dos órgãos públicos frente ao planejamento e manutenção desse tipo de projeto (RIBEIRO; VARELA, 2015). 
Por conseguinte, o Quadro 3 apresenta os principais comentários dos deficientes sobre as experiências vivenciadas em seus trajetos em áreas arborizadas.

\begin{tabular}{|c|c|c|}
\hline $\begin{array}{l}\text { Categoria } \\
\text { Analisada }\end{array}$ & Homens (H) & Mulheres (M) \\
\hline & $\begin{array}{l}\text { - "Uma vez, antes de me acostumar com o local } \\
\text { que faz parte do meu trajeto diário, um galho com } \\
\text { espinho alcançou meu rosto, ao tentar desviar } \\
\text { machuquei meu pé, pois tinha um canteiro de } \\
\text { plantas com espinhos. Também já escorreguei em } \\
\text { um fruto arredondado e grande de uma árvore } \\
\text { plantada na calçada." (H1); } \\
\text { - "Já tropecei em raízes e buracos, por isso tenho } \\
\text { medo de caminhar sozinho, quase cai..." (H2); } \\
\text { - "Nunca me machuquei, mas já cai, mas muitas } \\
\text { vezes percebo que as raízes quebram a calçada e } \\
\text { danificam o piso tátil, isso atrapalha muito a nossa } \\
\text { orientação..." (H3); } \\
\text { - "Já fiquei sem conseguir passar em um local } \\
\text { onde a árvore ocupava grande parte da calçada e } \\
\text { precisei da ajuda de outros pedestres, mas nem } \\
\text { sempre encontramos quem nos ajude no } \\
\text { momento." (H4); } \\
\text { - "Uma vez bati com a cara em um galho que era } \\
\text { muito baixo. Também já fui atingido por um tronco } \\
\text { que foi cortado, um toco..." (H5); } \\
\text { - "...Mesmo andando acompanhado, as vezes é } \\
\text { difícil a passagem perto de árvores, todo cuidado é } \\
\text { pouco..." (H6); } \\
\text { - "As raízes, buracos e galhos baixos sempre me } \\
\text { atrapalham, não me acostumo..." (H7); } \\
\text { - "Não passei por experiências negativas ou } \\
\text { acidentes, mas sei que atrapalha muitos cegos." } \\
\text { (H8). }\end{array}$ & $\begin{array}{l}\text { - "Como ando acompanhada } \\
\text { tenho ajuda para desviar das } \\
\text { árvores, galhos e buracos, mas } \\
\text { sozinha eu teria muita } \\
\text { dificuldade." (M1); } \\
\text { - “... escorreguei em frutos no } \\
\text { chão, galhos já bateram no meu } \\
\text { rosto, mas não me feriu..." (M2); } \\
\text { - "Nunca cai, me feri ou } \\
\text { machuquei. Onde eu caminho as } \\
\text { árvores são bem plantadas, eu } \\
\text { acho." (M3); } \\
\text { - "Mesmo acompanhada ainda } \\
\text { tropeço nos buracos e raízes... as } \\
\text { vezes quem está comigo pede } \\
\text { que eu abaixe." (M4); } \\
\text { - "As árvores são grandes e as } \\
\text { calçadas pequenas, falta espaço } \\
\text { para a passagem." (M5); } \\
\text { - "Tenho dificuldades quando } \\
\text { tomam o espaço da calçada." } \\
\text { (M6); } \\
\text { - "Sempre tenho ajuda para } \\
\text { caminhar e desviar das árvores, } \\
\text { mas sei que é difícil para quem } \\
\text { quer autonomia... A gente quer } \\
\text { ser independente, andar sozinho } \\
\text { com segurança..." (M7). }\end{array}$ \\
\hline
\end{tabular}

Quadro 3. Experiências positivas e negativas com a arborização urbana

Chart 3. Positive and negative experiences with urban afforestation

Infere-se que as mulheres cegas apresentam opiniões semelhantes às dos homens cegos no que diz respeito à interferência da arborização, quando não atende às normas técnicas brasileiras de acessibilidade e legislação vigente, no nível de mobilidade dos sujeitos com déficits visuais, pois é notável, nas falas dos indivíduos de ambos os gêneros, a repetição de termos e/ou frases do tipo: "atrapalha", "é difícil a passagem", "tropecei”, "caí", "tomam o espaço da calçada", "tenho dificuldade", entre muitos outros fatores explicitados..

Percebe-se ainda, que alguns indivíduos que já passaram por situações conflituosas como tropeços em raízes, impossibilidade de caminhar com árvores obstruindo a passagem, 
quedas e afins, sofreram certo impacto psicológico, uma vez que estes afirmam que sentem medo de caminhar em locais arborizados, pois temem cair e se machucar.

Dessa forma, tal fato entra em consonância com as formulações de Duarte e Cohen (2014), que destacam que as interferências dos obstáculos impostos à circulação dos deficientes nos espaços públicos vão muito além do fato de limitações à locomoção, isto é, tal fato gera um eventual desgaste emocional, fazendo com que esses sujeitos sintam-se incapazes, desmotivados, e, sobretudo, que desenvolvam estresse, tendo em vista que não conseguir se locomover autonomamente em determinados locais, leva o deficiente a uma situação de frustração, insegurança e desmotivação.

Cabe destacar que, as normas e leis que regem o direito à locomoção nos espaços públicos também se aplicam ao planejamento da arborização, e tais normas parte de tal processo. Ademais, para uma boa gestão, não se deve privilegiar o plantio de árvores em detrimento da acessibilidade e locomoção, tampouco deve priorizar a redução de barreiras físicas e eliminar a arborização. Percebe-se a necessidade de equilíbrio, isto é, ambos os mecanismos devem existir no espaço público de forma sinérgica. Assim, as políticas públicas devem garantir, simultaneamente, tanto a gestão ambiental urbana e manutenção das espécies vegetais, quanto a livre circulação de pedestres, sem que haja interferências.

Entrementes, se fosse possível difundir nos órgãos responsáveis pelo planejamento da arborização, bem como no governo municipal, uma palavra e/ou termo refletido nestes resultados e que retrata a situação da arborização vinculada à acessibilidade de pessoas com deficiência ou com mobilidade reduzida no âmbito urbano local, o termo escolhido, metaforicamente, seria "miopia", pois apesar da problemática estar presente em Natal/RN, sendo bastante vivenciada pelos deficientes, parece haver a visão curta de muitos órgãos responsáveis, fato que impede a definição e efetivação da arborização adequadamente.

Embora ainda exista uma lacuna nas bases de pesquisa sobre a situação que envolve arborização e (In) acessibilidade, o problema é recorrente e pode ser observado em grandes ou pequenas cidades, tendo em vista que em qualquer logradouro torna-se comum a presença de árvores em lugares errados que podem ocasionar a obstrução de passagem, interrompendo a livre circulação, e, consequentemente, se configurando como barreiras físicas que dificultam sobremaneira o acesso, e em certos casos, impossibilitam a livre e segura locomoção.

No que tange à satisfação desses indivíduos com relação à situação da arborização na cidade de Natal/RN, o Quadro 4 traz uma descrição dos principais comentários resultantes da entrevista. 


\begin{tabular}{|c|c|c|}
\hline & Homens $(\mathrm{H})$ & Mulheres (M) \\
\hline Satisfação & $\begin{array}{l}\text { - "Parcialmente satisfeito, pois muitas árvores } \\
\text { representam conflitos para a locomoção, sinto } \\
\text { isso diariamente, só nós deficientes } \\
\text { sabemos... Acho que os responsáveis } \\
\text { poderiam buscar avaliar nossa opinião." (H1); } \\
\text { - "Insatisfeito, porque não pensam nos } \\
\text { deficientes. Acho que deviam se importar mais } \\
\text { com a gente." (H2); } \\
\text { - "Insatisfeito. Um descaso." (H3); } \\
\text { - "Nem satisfeito nem insatisfeito. Os } \\
\text { responsáveis devem mudar isso, analisar a } \\
\text { situação, porque sofremos duplamente: com a } \\
\text { deficiência e com a falta de adequações nas } \\
\text { ruas." (H4); } \\
\text { - "Insatisfeito em partes. Árvores são boas } \\
\text { para a cidade, mas não devem interferir na } \\
\text { vida dos pedestres. A prefeitura deve avaliar a } \\
\text { situação." (H5); } \\
\text { - "Não me sinto satisfeito. Gosto de árvores, } \\
\text { mas a situação poderia ser melhorada, cortar } \\
\text { galhos, podar direito..." (H6); } \\
\text { - "Insatisfeito. Precisa de melhorias porque } \\
\text { causa transtorno todo dia" (H7); } \\
\text { - "Parcialmente satisfeito. Há locais bons de } \\
\text { trafegar e outros complicados, acho que } \\
\text { devem igualar, padronizar." (H8). }\end{array}$ & $\begin{array}{l}\text { - "Insatisfeita. Acho que os } \\
\text { responsáveis poderiam buscar } \\
\text { nossa opinião para realizar esses } \\
\text { plantios." (M1); } \\
\text { - "Nem satisfeita nem insatisfeita. } \\
\text { Só acho que às vezes sofremos } \\
\text { para caminhar em alguns lugares } \\
\text { com árvores, podia ser melhor." } \\
\text { (M2); } \\
\text { - "Parcialmente satisfeita. Não } \\
\text { tenho muitas reclamações. } \\
\text { Melhorias sempre é bom." (M3); } \\
\text { - "Insatisfeita. Não se preocupam } \\
\text { com a gente. Tenho medo de sair } \\
\text { só, cair, porque sei como a } \\
\text { situação é ruim dessas árvores } \\
\text { grandes nas calçadas estreitas" } \\
\text { (M4); } \\
\text { - "Não sei, acho que podiam } \\
\text { plantar árvores menores nas } \\
\text { calçadas pequenas, seria bom." } \\
\text { (M5); } \\
\text { - "Nem satisfeita nem insatisfeita. } \\
\text { Sem sugestões." (M6); } \\
\text { - "Insatisfeita. As consequências } \\
\text { são permanentes, até depois das } \\
\text { podas e cortes..." (M7). }\end{array}$ \\
\hline
\end{tabular}

Quadro 4. Satisfação com a arborização urbana

Chart 4. Satisfaction with urban afforestation

A insatisfação expressiva dos envolvidos demonstra falhas na condução dos projetos de arborização local. Ademais alguns aspectos identificados nas respostas são preocupantes, por exemplo, o termo "descaso", utilizado pelo indivíduo H3; "não pensam nos deficientes" destacado pelo indivíduo $\mathrm{H} 2$; "sofremos duplamente", colocado por H4; "poderiam buscar nossa opinião", mencionado por M1; "só nós sabemos", destacado por $\mathrm{H} 1$, entre outras passagens dos comentários, demonstram que estes indivíduos sentem-se excluídos em virtude das dificuldades enfrentadas com a presença de árvores que não cumprem as exigências legais e normas técnicas, bem como gostariam de ser ouvidos e suas opiniões consideradas no momento de planejamento e implementação da arborização. Desta forma, atentar para a inclusão, necessidades de todos os cidadãos e cumprir diversas leis torna-se fundamental para evitar esse tipo de inconveniente (SILVA; FIDELIS; CASTRO, 2011; BATISTA et al., 2013; SOARES; ALVES, 2016; OLIVEIRA et al., 2017).

Um aspecto comum nas falas dos indivíduos H1 e M1 trata-se do apelo "poderiam buscar nossa opinião", e H1 ainda reforça "só nós deficientes sabemos", revela que os 
cidadãos que vivenciam diariamente situações, positivas ou negativas, envolvendo a arborização urbana, são os mais conhecedores da referida realidade, e os órgãos responsáveis devem, portanto, avaliar as experiências de tais sujeitos, ou seja, torna-se importante investigar como as pessoas com deficiência ou com mobilidade reduzida, bem como a população no geral, enxergam a situação (PIZZIOLO et al., 2014; GERSTENBER; HOFMANN, 2016).

Julga-se importante explanar com um pouco mais de detalhes a indagação de $M 7$, que menciona "as consequências são permanentes, até depois das podas e cortes", e tal afirmação vai de encontro com a crítica realidade das podas e cortes, pois muitas vezes estas são realizadas sem suporte técnico, até mesmo algum morador local para amenizar os transtornos pode realizar podas, todavia, o que poderia se tornar uma boa ação, acaba por ocasionar muitos transtornos. Desta forma, inegavelmente, é preciso que haja um trabalho maior de fiscalização desse tipo de ação e do bom posicionamento desses cortes e podas quando necessários, pois de fato, como mencionado pela referida pessoa com deficiência, as consequências são permanentes. De forma análoga, deve-se avaliar a situação de plantio, isto é, todas as árvores plantadas são de responsabilidade dos órgãos públicos? Será que moradores tomam a liberdade de plantar árvores aleatoriamente? Estas e outras questões merecem atenção.

Retomando as evidências científicas obtidas com os relatos expostos anteriormente, que trata do gosto por caminhar em áreas com árvores, pode-se destacar o expressivo gosto dos envolvidos pelo aspecto arborização, tendo em vista que uma passagem que se repetiu bastante nas falas os sujeitos foi, "gosto, mas", ou seja, tais indivíduos reconhecem e são favoráveis à manutenção da arborização como mecanismo de regulação climática, provedor de sombra e melhoria da qualidade de vida urbana, todavia sentem-se afetados por este processo.

Nesta perspectiva, a proposta deste trabalho, não consiste em mostrar o lado negativo da arborização, tampouco, sugerir que a mesma deve ser eliminada. Pelo contrário, conhecendo-se o potencial da existência de árvores no ambiente urbano, incentiva-se o levantamento de medidas que busquem a melhoria desse paradigma, de modo que esteja alinhado às necessidades de todos os cidadãos, para que desta forma, todos possam usufruir dos seus benefícios socioambientais.

Embora este trabalho se configure como uma primeira tentativa de levantar evidências científicas sobre os impactos da arborização especificamente no dia a dia de pessoas com deficiência visual, pode-se inferir que se obteve resultados relevantes para o contexto, que demonstram uma realidade que muitas vezes não é percebida pela administração pública, bem como por grande parte da população que não possui déficits sensoriais. Apesar dos resultados serem locais, esta pesquisa pode ser expandida para outros contextos, envolvendo maior 
aproveitamento dos dados, ampliação das bases de dados, bem como, mapeamento do processo de arborização, de modo que se possa identificar eventuais conflitos entre a existência de espécies arbóreas e a locomoção de pedestres, sobretudo de deficientes visuais, propondo assim, melhorias contínuas.

\section{CONCLUSÕES}

Constatou-se que a arborização urbana, quando implantada de forma inadequada, afeta o nível de mobilidade de pessoas com deficiência visual nas vias públicas. A percepção de alguns dos indivíduos que participaram da pesquisa, deixou explícito o sentimento de medo e vulnerabilidade ao caminharem em locais com espécies arbóreas plantadas sem padronização e planejamento prévio. Tal fato demonstra a dificuldade de locomoção de tais sujeitos, denotando a necessidade de reforçar as políticas públicas e maior atenção no que tange ao acompanhamento por parte dos órgãos responsáveis.

Percebe-se ainda, que há um sentimento de exclusão por parte das pessoas com deficiência visual, que consideram que o poder público deveria ouvi-los, intervir e avaliar a situação vigente, determinando melhorias, e analisando o processo continuamente para evitar os transtornos elucidados. Ademais, o tema, embora conte com publicações relevantes na literatura, ainda apresenta lacunas que fazem dele um campo de estudo amplo e inacabado.

Por conseguinte, evidencia-se que apesar de gostarem das áreas arborizadas e reconhecerem sua importância, a ausência de medidas de acompanhamento do processo de plantio e manutenção, que contemple a acessibilidade, acarreta um desgaste físico e psicológico para a pessoa com deficiência visual, que teme cair e/ou machucar-se, logo, caminhar em áreas com árvores passa a ser uma tarefa árdua que acaba comprometendo a qualidade de vida de tais sujeitos e reduz de forma impactante a independência e a segurança na locomoção. Conclui-se que a administração pública precisa planejar e adotar medidas por meio da elaboração de políticas públicas que assegurem a manutenção da arborização urbana em harmonia com o respeito às limitações de cidadãos com deficiência ou com mobilidade reduzida, bem como dos demais pedestres. 


\section{REFERÊNCIAS}

ARMSON, D. P.; STRINGER, P.; ENNOS, A. R. The effect of street trees and amenity grass on urban surface water runoff in Manchester, UK. Urban Forestry \& Greening, Amsterdã, v. 12, n. 3, p. 282-286, 2013.

BARDIN, L. Análise de Conteúdo. Lisboa: Edições 70, 2002.

BATISTA, F. A.; CHAVES, T. P.; FELISMINI, D. C.; DANTAS, I. C. Inventário quali-quantitativo da arborização urbana na cidade de Remígio, Paraíba. Revista de Biologia e Farmácia, Campina Grande, v. 9, n. 1, p. 70-83, 2013.

DUARTE, C. R. S.; COHEN, R. Metodologia para Diagnóstico de Acessibilidade em Centros Urbanos: Análise da Área Central da Cidade do Rio de Janeiro. Revista Gestão \& Conexões, Vitoria, v. 3, n. 1, p. 142-146, 2014.

FARIA, D. C.; DUARTE, J. M. A.; PINTO, D. M.; ALMEIDA, F. S. Arborização Urbana no Município de Três Rios-RJ: Espécies utilizadas e a Percepção de seus Benefícios pela População. Revista da Sociedade Brasileira de Arborização Úrbana, Piracicaba, v. 8, n. 2, p. 58-67, 2013.

GERSTENBER, T.; HOFMANN, M. Perception and preference of trees: A psychological contribution to tree species selection in urban areas. Urban Forestry \& Urban Greening, Amsterdã, v. 15, n. 1, p. 103-111, 2016.

GIL, A. C. Como elaborar projetos de pesquisas. São Paulo: Atlas, 2002.

GODECKE, M. V.; MAURÍCIO, G. N. Guia para planos ambientais municipais. Pelotas: Santa Cruz, 2015.

HAUBRICHT, D. M.; FIORINI, F. A. Percepção ambiental dos moradores do assentamento Vila Rural I do município de Alta Floresta - MT. Revista da Universidade Vale do Rio Verde, Três Corações, v. 12, n. 1, p. 248-256, 2014.

KRAMER, J. A.; KRUPEK, R. A. Caracterização florística e ecológica da arborização de praças públicas do município de Guarapuava, PR. Revista Árvore, Viçosa, v. 36, n. 4, p. 647-658, 2012.

LICHT, C. B. Turismo e Inclusão Social: um estudo de caso sobre a estrutura da cidade de Porto Alegre para receber turistas com deficiência ou mobilidade reduzida. Fólio-Revista Científica Digital-Jornalismo, Publicidade e Turismo, Porto Alegre, v. 1, n. 1, p. 112-131, 2015.

OLIVEIRA, A. F.; PEREIRA, G. A.; SANTOS, E.; OLIVEIRA, K. D. S.; POMPERMAYER, R. S.; COELHO, S. J.; PEREIRA, J. A. A. Arborização Viária Conflituosa com a Rede Elétrica na Região Oeste de Belo Horizonte - MG. Revista da Sociedade Brasileira de Arborização Urbana, Piracicaba, v. 11, n. 2, p. 27-44, $2016 a$.

OLIVEIRA, L. M.; SANTOS, A. S.; SOUZA, P. A.; ALVES, K. C. C. L. F.; GIONGO, M. Diagnóstico da Arborização nas Calçadas de Gurupi, TO. Revista da Sociedade Brasileira de Arborização Urbana, Piracicaba, v. 12, n. 1, p. 105-121, 2017. 
OLIVEIRA, R. J.; SILVA, A. L. A.; SILVA, E. O.; SANT'ANNA, G. L.; FRANÇA, L. C. J. Gestão e Avaliação da Arborização de Áreas Públicas no Município de Bom Jesus-Jesus-PIAUI. Revista Brasileira de Agropecuária Sustentável (RBAS), Viçosa, v. 6, n. 1, p. 9-14, 2016b.

PIZZIOLO, B. V.; TOSTES, R.; SILVA, K.; ARRUDA, V. M. Arborização urbana: percepção ambiental dos moradores dos bairros Bom Pastor e Centro da cidade de Ubá/MG. Revista Eletrônica em Gestão, Educação e Tecnologia Ambiental, Santa Maria, v. 18, n. 3, p. 11621169, 2014.

RIBEIRO, V. C.; VARELA, S. Acessibilidade nas calçadas urbanas de uma cidade da Serra Catarinense. Revista GepesVida, Lages, v. 1, n. 2, 2015.

RIBEIRO, F. A. B. S. Arborização urbana em Uberlândia: percepção da população. Revista da Católica, Uberlândia, v. 1, n. 1, p. 224-237, 2009.

RUOSO, D. A percepção climática da população urbana de Santa Cruz do Sul/RS. Revista RA'E GA, Curitiba, v. 25, n. 1, p. 64-91, 2012.

SANTOS, C. Z. A.; FERREIRA, R. A.; SANTOS, L. R.; SANTOS, L. I.; GOMES, S. H.; GRAÇA, D. A. S. Análise Qualitativa da Arborização Urbana de 25 Vias Públicas da Cidade de Aracajú SE. Revista Ciência Florestal, Santa Maria, v. 25, n. 3, p. 751-763, 2015.

SILVA, F. F.; FIDELIS, M. E. A.; CASTRO, P. F. Arborização e acessibilidade em calçada: comentários sobre o deslocamento entre Campi da Universidade Federal Fluminense. Revista da Sociedade Brasileira de Arborização Urbana, Piracicaba, v. 6, n. 3, p. 43-63, 2011.

SOARES, A. M. J.; ALVES, R. L. Impactos da Arborização no Dia a Dia de deficientes Visuais: aspectos da gestão ambiental urbana vinculada à acessibilidade. In: CONGRESSO BRASILEIRO DE GESTÃO AMBIENTAL, 7., 2016, Campina Grande. Anais... Campina Grande: IBEAS, 2016.

YIN, R. K. Estudo de Caso: Planejamento e Métodos. 4. ed. Porto Alegre: Bookman, 2010. 